\title{
Effect of Audience on Concentration and Attentional Demands on the Performance of Athletes on Railwalking by Athletes of the University of Ibadan, Ibadan, Nigeria
}

\author{
Dr. Ben Ohuruogu \\ Ebonyi State University, Abakaliki, Nigeria \\ Dr. Mong Emeka \\ Ebonyi State University, Abakaliki, Nigeria \\ Alor Roseline Chinyere. \\ Ebonyi State College of Education, Ikwo, Ebonyi, Nigeria \\ Ogbonna Raphael Nwodeh \\ Ebonyi State College of Education, Ikwo, Ebonyi, Nigeria
}

\begin{abstract}
Attention and concentration are crucial indices for successful performance outcome in sports. Therefore, the ability of an athlete to control and maintain attention and concentration for the duration of the athletic competition is often difficult, this may be due to the influence of the audience and significant others which often affects their performance. The study therefore examined the audience effects on attentional and concentration demands of the athletes in the performance of a motor skill (Railwalking) by selected athletes in University of Ibadan. The randomized pre-test, post-test control and experimental group design was used in the study. Forty (40) male athletes, which constituted the samples for the study, they were randomly assigned to each of the two experimental and control groups. Test instrument in railwalking used in the study were standardized. Analysis of covariance (ANCOVA), was the main statistical method use sin the study. To determine the effect of the two audiences (volitional and captive). All the hypotheses were tested at 0.05 level of significance. The findings revealed that volitional audience had significant effect on the athletes performance on railwalking $(\mathrm{F}=8.20 ; \mathrm{P}$ $<.0 .05)$. The captive audience also had significant effect of on railwalking $(\mathrm{F}=75.93 ; \mathrm{P}<0.05)$ but, there was no significant effect on athletes performance on railwalking when the captive and volitional audience where combined. $(\mathrm{F}=43.80 ; \mathrm{P}<0.05)$. The study established that for a high performance of any motor skill, whether fine or gross in nature, the athletes should be provided with the relevant cues that can and performance. It was, therefore, recommended that coaches, sports trainers, and sports psychologist should expose their athletes to similar environmental and captive audience conditions during practice and training sessions as they occur in real competition.
\end{abstract}

DOI: $10.7176 / \mathrm{JBAH} / 10-2-04$

Publication date: January $31^{\text {st }} 2020$

\section{INTRODUCTION}

The experience of the athletes in terms of frequency and duration of exposure to performance front of crowds, the impact of performing in front of talent scrub (or other knowledgeable people) versus an audience largely ignorant of the intricacies of the performance, the audience size and the atmosphere" of the venue, and the interactivity and perceived support of the audience with the competitors are all factors that adds pressure on an athletes. All these leaves to anxious moments for athletes. As anxiety theories postulate, too much anxiety can lead to poor performance. Therefore no social psychological effect is more important to athletic performance and outcome than the audience or spectator effect. There is significant advantage in playing at home in soccer, baseball, basketball and in other competitive sports. While many variables may help create the home court or field advantage, none seems to be as important as the presence of a supportive audience as this determine that audience presence could affects athletic performance (Pollard, 1986). It has been nearly everyone's experience to know individuals who can demonstrate a high degree of skill proficiency when performing alone or in the comfortable confines of a practice situation but who disintegrates during actual competition and in front of an audience. By the same token, there are those people whose performance improves under this circumstance; because of the complexity of the human organism and the degree to which a skill may have been learned, the presence or absence of spectators will often times have unpredictable effects on different people.

Generally speaking, excluding such factors as skill complexity, degree of skill attainment, and the person's anxiety level, the presence of others is usually found to have a stimulating effect on performance.There is ample evidence to show that a supportive audience can aid the performance of home team, whereas one might expect 
that an increase in the size of an audience or the numbers of participants (co-actors) would automatically increase the arousal level, hence the social facilitation effect. For example, the number of people in an audience and motor performance is also equivocal as McCullagh and Landers (1976), and Wankel (1977) variously state that audience size is related to good performance as the winning percentage of the home teams increased as the size of the crowd increased, whereas, Schwartz and Barsky (1977), and Edwards (1979) opine that such factors as audience density and audience intimacy may be more important than size for creating the advantage in basketball and ice-hockey where the fans are often very close and intimate with the athletes.

Emenike (1985) compared the effectiveness of audience and non-audience on sports performance where two groups of supportive and non-audience atmosphere were the conditions set out, he posited that an individual, according to his or her personality either positively or negatively at any material time, and that the closeness of the audience to the athlete and the athlete's feeling about the crowd have varied influences. He advocates for a closer study instructor, so as to understand their (athletes) attitudes and characteristics before an audience by placing inexperienced athletes in front of groups and gradually increasing the size during the initial weeks, months of practice. He suggests that:

a. Athletes should be taught the skills properly;

b. Skills should be over learned;

c. Athletes should be informed and made to understand the likely audience experiences they would encounter during the actual competition stages;

d. Athletes be exposed to on lookers during training session;

e. Athletes should have mental focus and psychological acclimatization of audience effects - of any size.

Hardy and Crace (1991) assert however that the presence of an audience of one or more spectators can facilitate performance, as almost everyone has experienced the desire to perform better when friends family or members of opposite gender are watching. This assertion leads credence to how Iwuanyawu, national Football Club of Imo State in the Global com premier league week 34, as reported by Osuji (2004), our boys failed us. They failed to come out fully to match Dolphin grit for girl. They seemed to have been swallowed by the atmosphere of the big occasion - but the player lost concentration, perhaps, because of stage fright in a game that so much was at stake for both teams - coupled with the presence of the massive home crowd, it is quite regrettable we lost that game (four goals to Nill)".

One of the outstanding qualities of a successful athlete is his ability to perform and perform well before numerous spectators whereas non-athletes would find their performance of athletic skills hampered under the presence and stress of having a vociferous audience. Superior athletes either appear to be oblivious of their environment during a contest or do better than in practice. Whereas others are distracted by noise and another factors.

Some people feel that athletes can generally perform any skill well before a crowd but if the theory discussed above holds true, the performance of newly acquired skills would not be enhanced by the presence of spectators even if the subjects are athletes. The theory was upheld in an experiment undertaken by Singer (1965) where sixteen Ohio State University athletes from a variety of sports and sixteen non-athletes learned how to walk on a balance rail. All the subjects were given 10 trials to learn the task alone and three trials before a group of passive spectators. The three trials in the presence of others actually resulted in generally poorer performance than on the trial immediately proceeding, which was executed without the audience.In addition, the non-athletes performed better than the athletes in two of the three trials performed in front of the spectators.

Kozan (1973) did not find any significant difference in the performance outcomes between subjects who learned a task (balancing on a balance rail) alone and in the presence of encouraging or critical spectators. For the absence of a difference between subjects who learned alone and subjects who learned in the presence of others, he put forward the possibility that subjects in the "alone" condition had imagined "spectators" for themselves and the performance of others on the task. Apparently other subjects functioned as a reference framework while this explanation is an adhoc kind, it is meaningful in that it implies that a performance can, in retrospect be looked at or appraised and that this can lead to an increase in the level of activation. After all, sporting achievements are often followed in precisely diverse sports, that is to say, outside the framework of the actual availability of spectators.

Landers (1980) points to a second important consequence of an audience namely, distracting (from the task) effects. On the basis of this, Lander considers it necessary for a shift in related research to place from the motor (i.e output) to the perceptual (i.e input) said. The consequence of the availability of an audience on the carryout of the task will not be primarily dependent on the dominant response of the subject but much more on the amount of attention that is required to carry out the task. The increase in the level of activities as a consequence of the presence of spectators has an influence on performance (Easterbrook, 1989). Tasks demanding relatively little attention before an audience might lead to better performances. Naturally, this will hold more reason often for tasks that are already learned and are under control than for tasks in which the athletes is still in the learning phase. Attempts to distract table tennis players by means of noise, music prodding with a stick, to unbalance by 
pushing or pulling or by requiring a secondary task to be carried out during play (sums to workout), did not seem to be in any way successfully (Blitz, 1980). In the practical situations, it is apparent that in some sports, attentional or concentration disturbances are easier to be noticed than in others. Therefore, it implies that an athlete is expected to perform intricate motor skills in front of any type of spectators after a full mastery of the skills.

Singer (1965) attempts to determine the effect of spectator presence on athletesand non-athletesperforming a novel motor task. A stabilometer, requiring balance ability was the task practiced by the subjects alone in one day and in front of a group of spectators, the next day. The athletes represented various sports at Ohio State University and were acknowledge as being among the best athletes at the university. The non-athletes were observed to perform significantly better than the athletes in front of the audience. Apparently, there was no positive transfer effect for the athletes who were used to displaying their motor abilities before spectators possibly, athletes are more sensitive to people watching them perform and feel uncomfortable demonstrating before a group, a skill at which they are not extremely competent. Even when practicing alone, the athletes did not show superior balancing ability.

\section{Statement of the Problem}

It is in the light of the above statement that the researcher set out in this study to determine the audience effect on athletes performing a skill under various types of audience in order to subsequently improve performance when distracting intervening variables of noise (audience) conditions are introduced at a later stage (of the competitions) the study also sought to determine whether the presence of this audience under any condition) would affect the performance of the motor skill of railwalking.

\section{Research Hypotheses}

The following hypotheses were tested

1. There is no significant effect of volitional audience on the performance of athletes on railwalking

2. There is no significant effect of captive audience on the performance of athletes on railwalking

3. There is no significant effect of volitional and captive audience on the performance of athletes on railwalking

\section{Significance of the Study}

The presence of an audience of one or more spectators can facilitate performance, as almost everyone has experienced the desire to perform better when friends, family or members of opposite sex are watching. It is therefore hoped, that the findings of this study would assist coaches and sports psychologists in the formulation of policies and principles in the control of stress and anxiety, before, during and after major competitions.

It is also hoped that this study would help athletes in overcoming tensions and anxiety often experienced when one suddenly appears before a large crowed.

The findings of this study would invariably add to the existing body of knowledge in understanding the functions of the human mind during the performance of any motor skill before different kinds of spectator.

\section{Research Design}

The randomized pre-test-post-test control and experimental group research design was used for this study. Participants were randomly, selected to take part in the study. They all had an equal chance of selection to the experimental and control groups.

Thomas and Nelson (2001) states that this design has the unique characteristics of being restrictive to the various groups in the study and has been found to minimize any extraneous variables of contamination and maturation effect.A Pre-test was conducted and followed by the post test after eight weeks of distributed practice sessions.

\section{Population}

The population for this study consisted all matriculated undergraduate male athletes of the University of Ibadan, Ibadan, who were bona fide students and represented either their Halls of Residence at inter Hall competitions, faculties during inter faculties competition and/or the University at any athletes competitions.

\section{Sample and Sampling Techniques}

A total of twenty (20) students were used for this study the purposive sampling technique was used in selecting the sports men who took part in the study. Prior to the commencement of the experiment an anxiety test was administered on the subjects. Those who score 40-60 percent were used for the study. The fish-bowl method was used to assign the participants in the two categories of control and experimental groups of ten athletes per group. 


\section{Procedure for test Administration and Data Collections}

The study was carried out in two phases, the first phase was the administration of the anxiety scale test on the participants. This was done in order to determine the anxiety level of the participants. They were rated between to $40-60$ percent (moderate)and this used for the study. The second phase of the study was the pre-test sessions which lasted for two (2) weeks after which there was a break for 8 weeks to enable the experimental group go through the practice sessions of learning the selected motor skill of balance railwalking. After, the Eight (8) weeks, the post-test performance scores were collected from the two groups - control and experimental and used for data analysis.

\section{Procedure for Data Analysis}

The data collected for the study were analyzed using the SPSS/PC model of the University of Ibadan Computer centre, Ibadan.

The descriptive statistics of mean, standard deviation, and mean difference was employed to describe the characteristics of the groups. While the inferential statistics of the student ' $t$ ' test was used to determine the difference between the two groups. The analysis of covariance (ANCOVA) was employed for the groups comparison. All hypothesis was tested at 0.05 level of significance.

\section{Result and Discussions}

$\mathrm{H}_{01}$ : There is no significant effect of volitional audience in the performance of athletes onRailwalking.

Table 1 show the result of the volitional audience on the performance of Athletes on Rail walking. The covariates of 44.39 had $\mathrm{F}$ value of 25.41 at df, whereas the main effects on railwalking had 14.34 as sum of squares and $\mathrm{F}=8.21$, thereby indicating performing before the volitional audience had significant effect on the athletes in railwalking.

Hypothesis 1 which states that there is no significant effect of volitional audience on the performance of athletesonrailwalking is hereby rejected. The effects of the volitional audience is significant as it affected performance outcome.

The findings here does not agree with Kozan (1973), whose study on railwalking implied that there was no corresponding difference between subjects who learned alone and performed in the presence of an audience and those who learned with the audience in attendance. He attributed this to an increase in the level of activation, in this study, the presence of volitional audience could be said to have increased the arousal level of athletes and improved on their performance outcomes.

Landers (1980), considers the important consequences of an audience in distracting athletes from the task. He therefore considers it necessary for a shift from motor performance to the perceptual input of the athletes.

Table 1:

Summary of Analysis of Co-Variance (ANCOVA) on Effect of Volitional Audience on the performance of Athletes onRailwalking

\begin{tabular}{|l|l|l|l|l|l|l|}
\hline Sources of & Sum of & Df & Mean & F & Sign of F & Remarks \\
\hline Variation & Squares & square & & & & \\
\hline Covariates & 44.39 & 1 & 44.39 & 25.41 & .000 & \\
\hline Main effects & 14.34 & 1 & 14.34 & 8.21 & .007 & $*$ \\
\hline Explained & 58.74 & 2 & 29.37 & 16.81 & .000 & \\
\hline Residual & 64.65 & 37 & 1.75 & & & \\
\hline Total & $\mathbf{1 2 3 . 3 9}$ & $\mathbf{3 9}$ & $\mathbf{3 . 1 6 4}$ & & & \\
\hline
\end{tabular}

*= significant at 0.05 alpha level

$\mathrm{H}_{02}$ : There are no significant effect of captive audience on the performance of athletes onrailwalking.

Pre-Post -Test: Captive Audience: Railwalking

\begin{tabular}{|l|l|l|l|l|l|l|}
\hline Sources of & Sum of & Df & Mean & F & Sign of F & Remarks \\
\hline Variation & Squares & square & & & & \\
\hline Covariates & 16.89 & 1 & 16.89 & 15.20 & .000 & \\
\hline Main effects & 84.43 & 1 & 84.43 & 75.93 & .000 & \\
\hline Explained & 101.33 & 2 & 50.67 & 45.56 & .000 & $*$ \\
\hline Residual & 14.14 & 37 & 1.12 & & & \\
\hline Total & $\mathbf{1 4 2 . 4 7 7}$ & $\mathbf{3 9}$ & $\mathbf{3 . 6 5 3}$ & & & \\
\hline
\end{tabular}

\section{$*=$ Significant at 0.05 alpha level}

Table 2 shows that there was a significant effect captive audience on the performance of athletes on balance railwalking with a covariate sum of squares value of 16.89 and $F$ value of 15.20 at $1 \mathrm{df}$. The main effects on the groups was 84.43 with $(\mathrm{F}=75.93 \mathrm{P}<0.05)$. therefore hypothesis two which states that there is no significant effect of captive audience on the performance of athletes in railwalking is hereby rejected. 
The effect of captive audience in the performance of railwalking was uphold by Singer (1965) who claimed that there was a generally poorer performance in the presence of spectators than when it was executed without an audience. In this finding, mental training could enhanced performance according to the specific sports and the presence of an audience could have affected their performance also.

\section{Summary}

This study was carried out to determine whether the introduction of two audience conditions - volitional and captive - would have any significant effect on the performance of Railwalking by the athletes. There were twenty (20) athletes with 2 groups of ten (10) athletes in each group. The control group and the experimental group.

The randomized Pre-Post Control and experimental group research design was for this study to determine the influence of the dependent variable on the independent variable- in the various audience conditions.

Standardized instruments constructed and validated by Johnson and Nelson (1979) at $r=.82$ for railwalking with the split half method and panel of experts as criterions measures respectively.

Athletes performance in railwalking before a volitional $1 / 2$ audience $(\mathrm{F}=8.21, \mathrm{P}<0.05)$ : $\mathrm{V} 12 \mathrm{H}_{01}$ and Athletes performance in railwalking before a captive audience $(\mathrm{F}=75.93, \mathrm{P}<0.05$ shows a significant differences).

\section{Conclusion}

This study concludes that to achieve a high level of performance in any motor skill, Athletes should be exposed to distracters such as noise and spectators. The study revealed that there was significant effect on athletes performance in railwalking before a volitional and captive audience.

The finding demands that an environmental condition similar to real competition should be provided during practice sessions.

\section{Recommendation}

1. Teaching aids such as video tapes of all types should be employed to facilitate the learning of motor skills.

2. Determining how and why audience presence affects athletics performance should be made known to them.

\section{REFERENCES}

Casterbrook J. A. (1959), The effect of emotion on cue utilization and the organization of behaviour Psychological Review 66, 183 - 201

Ememke, E. U. (1985), Comparative effectiveness of Audience and non - audience on sports performance in A. S. Sohi, C. O. Udoh, L .O. Amusa, YomiAwosika and V. C. Igbanugo (Eds) West African Journal of physical and Health Education, 2, 37 -43.

Hardg, C. J and Crace, R. K. (1991), The effects of task structure and team male competence on social loafing, Journal of sports and Exercise Psychology 13, 372 - 381.

Johnson, B. L. and Nelson, J. K (1969), Practical measurement for evaluation in Physical Education. Minneopolis; Burgress Publishing Company.

Kozan, B. (1973), The effects of a supportive and non - supportive audience upon learning a gross motor skill, international Journal of sport Psychology, 4: 27 -28.

Landers, D. M. (1980), Motivation and Performance, The role of arousal and attentional factors. In W. F. Straub (ed). Sport Psychology: An analysis of athletesbehaviour, $91-125$.

McCllagh, P.D and Landers D. M. (1976), Size of audience and social facilitation. Perceptual and Motor Skills, 42; $1067-1070$.

Mclead, S. A. (2011) Social Facilitation, Retrieved from http//www.simply psychology org/socialfacilitation.html.

Pollard, R. (1986), Home advantage in soccer, A retrospective analysis, Journal of sports sciences; 4: 237 - 248.

Schwartz, B and Barsky, S. F. (1977), The home advantage: Social forces, 55(3) $641-661$ (http//dx.do:/10.2307/2577461).

Singer, R. N. (1965), effects of spectators on athletes and non-athletes performing a Gross motor task, Research Quarterly, 36, $473-482$.

Wankel, P. I (1967), Conception of Broad at narrow attention, Psychological Bulletin, 68; 417 -429. 